\title{
Critical Future Studies - A Thematic Introduction
}

\author{
By Michael Godhe \& Luke Goode
}

Our 2017 essay "Beyond Capitalist Realism - Why We Need Critical Future Studies" (Goode \& Godhe 2017), published in this journal, was intended as both a provocation and an invitation to scholars concerned with the ways in which cultural texts not only represent the future, but also actively shape it by opening up or closing down imaginative possibilities. The essays collected in this special section are both responses to our invitation and provocations in their own right. From our point of view, they each take Critical Future Studies forward and collectively augur well for the further development of this field.

This introductory essay contains three sections. First, we briefly situate Critical Future Studies within an intellectual and historical context. In the following section we discuss some relevant scholarship published very recently in cognate fields (specifically Anticipation Studies and Sociology) and which are pertinent to Critical Future Studies as a developing field of study. In the final section, we introduce the articles contained in this this special section: six diverse contributions on topics including green capitalism, artificial intelligence and automation, science fiction, post-scarcity societies and the future of work, and socialist futures.

\section{Looking backwards}

The future is ancient: prophecy, forecasting and foresight are as old as recorded human history. Already in the classic ancient civilisations, 'experts' made calculations for the ruling classes of assets like agricultural products and calculations for future needs and uses. The Bible prophesises the perdition of mankind 6000 years after Genesis, and in the Norse mythology mankind and the gods were heading toward Ragnarök, the destruction of the world. In the interface between the medieval times and the 'Modern Age', the prophecies of Nostradamus were

Godhe, Michael and Luke Goode: "Critical Future Studies - A Thematic Introduction", Culture Unbound, Volume 10, Issue 2, 2018: 151-162. Published by

Linköping University Electronic Press: http://www.cultureunbound.ep.liu.se 
filled with apocalyptic visions. In this sense, forecasting and foresight have long been entangled with visions of destruction or apocalypse.

But novel modes of future-thinking were, of course, integral to Western modernity (cf. Frängsmyr 1990): the future became subject to systematised analysis, ideals of rational planning came to the fore, and the idea of progress became a central animating myth.

The establishment of modern social science was, in large part, guided by the desire to steer society in preferable directions in the future (something we return to in the next section). Even the field of History, while ostensibly the study of the past, has often been guided by an implicit or even explicit orientation towards the future: the idea of 'learning from history' in order to shape a better future or at least to avert catastrophe. In the case of modern Futures Studies, there are, in fact, good reasons for saying that its emergence after WWII was, like the establishment of the United Nations, triggered by the need to avert further catastrophes on such a scale. But its orientation was not merely preventive. Futures Studies was also linked strongly to ideals of rational planning and the welfare state, as well as a belief in the social sciences as useful for steering society towards a brighter future.

What we call 'mainstream' (as opposed to 'Critical') Futures Studies is a broad field. Hyenjou Son (2015) provides a useful thumbnail sketch of Future Studies as developing "through a three-phase periodization": a mid-20th century phase focused on scientific and technological progress, concerned especially with forecasting and "rationalizing" visions of the future; a second phase beginning in the 1970s, increasingly concerned with global visions of the future and increasingly entwined with global business interests; and a third phase beginning in the 1990s, characterized by a fragmentation of views of the future and by the prevalence of neoliberal institutions and worldviews. Son's (necessarily simplified) schema, raises the issue of an "identity crisis" within Futures Studies during this third phase.

In recent years, there's been a renewed interest in the future, and Critical $\mathrm{Fu}$ ture Studies (CFS) is part of that movement. Put simply, we see CFS involving the exploration and interrogation of ways in which society thinks, imagines and talks about the future - not the future singular, but possible futures. The objects of analysis for CFS include discourses, images and ideas about the future produced from within science (in the broadest sense, including the social sciences), and from futurology, of course. But it is also strongly interested in, and takes seriously the role of, popular culture including popular science, science fiction, news and technology journalism: in other words, we are not only interested in expert domains but also popular discourses that reach the public at large.

This interest in popular discourse is connected to an ethical commitment that we argued should be fundamental to CFS, namely, valuing the widest possible repertoire of ideas about possible futures. This is essential because, despite what 
futurists or Silicon Valley gurus might tell us, there's little that is inevitable or even predictable about the future. Of course, the future is in many ways subject to colonisation by powerful present-day interests: from inaction on climate change to the tendency to lock ourselves into dependence on certain technological pathways (such as a largely privatised internet infrastructure). But from a CFS standpoint, imagined futures are always contestable. So, rather than being just a dispassionate academic interest, the work of CFS reflects a certain ethical commitment to the notion of a 'futural public sphere' in which there is the widest possible public engagement with the widest possible repertoire of imagined futures. This means that CFS isn't dedicated solely to the deconstruction of futuristic texts and imaginings, exposing their biases, limitations, contradictions or interest-positions - although we see that work as vital; for us, CFS also has a reconstructive impulse in its ethical commitment to expanding, rather than narrowing, futural frames of reference and possibility.

And it follows from all of this that CFS work is not just about cultural texts themselves, but also with their surrounding power structures. Who can speak with authority and legitimacy about the future? Whose imagined futures are deemed possible or plausible, and whose are silenced or dismissed as unrealistic and impractical? Who benefits from promoting particular visions of the future? And where do these ideas and visions of the future come from (for they all have histories and genealogies that often go unacknowledged)? These are key critical questions that CFS scholars can and should ask about both futurescapes and the institutions that produce them (cf. Goode \& Godhe 2017: 109, 120-123).

\section{Looking outwards}

In our original essay on Critical Future Studies we argued that, while there is never a bad time to interrogate imagined futures, now there is something especially timely in the call for more sustained and critical scholarly engagement with the future in the Humanities and Social Sciences. Around the same time, however, some interesting and promising signs of renewed energies in this direction were already emerging. While we failed to account fully for these developments occurring in our peripheral vision, they are extremely encouraging and reinforce our sense that, when it comes to critical perspectives on the future, there is no time like the present.

The first area we should acknowledge is the inter-disciplinary field emerging recently under the auspices of Anticipation Studies (cf. Poli 2010). This represents an ambitious effort to synthesise, or at least bring into dialogue, knowledge and research surrounding anticipatory systems across the natural and human sciences: anticipatory dynamics are to be found in biological systems, for example, as 
much as in social systems, and efforts to understand and theorise anticipation at a more holistic and inter-disciplinary scale are, in our view, both exciting and rich in potential. The genealogy of Anticipation Studies can be traced back to what we (rather awkwardly) labelled 'mainstream' futures studies, while it seeks to bring the latter into a closer relationship with more traditional academic disciplines and to enrich its scholarly grounding. Yet alongside this academic focus, there remains an important practical orientation. UNESCO has established a chair in Anticipation Studies (currently occupied by one of the field's founders, Robert Poli) as part of its commitment to develop a global 'futures literacy' strategy. The concept of 'futures literacies' is a promising one. It refers to the development of citizens' capacities for envisaging, evaluating and acting in relation to a range of possible futures, in the context of a world characterised by complexity, uncertainty and cultural diversity. Riel Miller, another leading figure in the field, is UNESCO's 'Head of Futures Literacy. He emphasises that futures literacies (what we might also refer to more broadly as the capacity for 'anticipatory agency') depends not simply on access to knowledge and education (Miller 2018): these are necessary but not sufficient resources for citizens seeking to make informed choices about the types of future they wish to pursue. Also vital, according to Miller, is the capacity to access and to build 'evocative stories' about the future that can motivate and mobilise, rendering potential futures tangible - not as outcome predictions, but as creative building blocks in the envisioning process (Miller 2007). This chimes strongly, for us, with the emphasis on imagination, storytelling and cultural texts that we pursued in our original essay, and also with Ruth Levitas' (2013) theory of utopia as method that we drew and continue to draw upon. If Anticipation Studies develops on the premise that science, knowledge and reason are also bound up with imagination, storytelling and affect, at least when it comes to human anticipatory systems, then it promises to be a field from which Critical Future Studies will draw heavily, and one to which CFS can, in turn, contribute.

A second contemporaneous development that we did not fully acknowledge at the time of our 2017 essay comes in the form of calls for renewed engagement with the future in the field of sociology. In 2015, Current Sociology published a monograph entitled "Future Moves: Forward-Oriented Studies of Culture, Society, and Technology" (volume 63, number 2), which started from the principle that "in order to enhance sociology's relevance, more explicit and direct engagements with the future are needed" (Schultz 2015: 130). And in 2017, the journal Sociological Review published a special issue (volume 65, number 3) entitled 'Futures in Question: Theories, Methods, Practices' which called for renewed sociological attention to futures, endorsing Barbara Adam's dictum that "a future-less sociology is increasingly hard to defend" (cited in Tutton 2017: 479). As a discipline, it is fair to say that sociology's dominant orientation in recent decades has been towards 
theories, histories and critiques of the present. This has not always been the case, however. As Richard Tutton points out, discipline 'forefathers' including Auguste Comte and Karl Marx "were concerned with both forecasting and actively shaping the future" (Tutton 2017: 479) - as an aside, we might also note that science fiction author and utopian futurist H.G. Wells saw himself as a 'sociologist' of the future (Levitas 2010; cf. Bowler 2017). A relatively short-lived revival of sociological concern for the future also occurred in the 1960s and 1970s through the influential work of Wendell Bell, among others (see Tutton 2017). But the dominant trend has been to avoid 'speculation' about the future as epistemologically suspect and the reputational risks associated with anything that smacks of futurology. Thankfully, this reticence to engage with the future has not been total - for example, in our original article we referred to (and we continue to be influenced and inspired by) the work of sociologists such as Barbara Adam (see Adam and Groves 2017) and Ruth Levitas (2013).

The two special issues mentioned above are extremely promising signs of a growing engagement with the future within sociology. But more than just reinforcing and encouraging our sense of timeliness, these interventions also raise some more substantive and important theoretical and methodological issues that are pertinent to Critical Future Studies as we conceive it. While we don't have the space here for detailed reviews and discussion, we do want to draw attention briefly to a few distinct but related themes that these publications foreground, because we believe it is necessary that ongoing work in Critical Future Studies proceed at least with their importance born in mind.

Sociological thinking about the future encourages us to take materiality or 'matter' seriously, even if our own culturally oriented scholarship focuses its attention mainly on the discursive and ideational spheres. It is notable that both issues strongly emphasise the work of cultural imagination and include analyses, for example, of utopian and dystopian popular culture texts. But they also situate this in the context of material practices and institutions. Tutton, for example, cites Adam and Groves' insistence that the future is not reducible to imagination (see Tutton 2017: 483) and their dismissal of the idealistic notion of 'open futures' - material practices, entrenched institutional dynamics and technological 'path dependencies' established in the past and present, ensure, for example, that a future without the perils of climate change has already been closed off as a possibility. Tutton's concern is to bring imagination and discourse back into the equation without, however, succumbing to the 'cybernetic' illusion of a smooth feedback loop between the material and the ideational of the sort that characterised the work of Bell and others in the 1970s: his challenge to us is, rather, to appreciate the complex 'entanglements' of the material and the 'discursive.' In an era of profound social complexity, a challenge for cultural scholars of the future, then, is to consi- 
der how the imagined futures we study might be entangled in (rather than just informing or inspiring) material practices, from consumer behaviour through to the development and enactment of government policy. This entanglement also goes beyond the realm of human action to include, for example, unintended ecological consequences of well-intentioned 'green' policies that, independent of human will, may end up shaping our future in unforseen ways.

This challenge to accept the messy relationships between ideas and materiality connects, then, to a broader theme evident in much of the recent sociological futures scholarship, namely, the issue of societal complexity and uncertainty: intractable, multiply determined social dynamics and problems (from ecological change to inter-cultural tensions inherent in global modernity) only lend themselves, at best, to partial and provisional 'solutions.' Schultz (2015: 132), for example, reminds us that under such conditions there is a pressing need for methodological pluralism. For critical futures scholars, this is a useful reminder that reinforces the value of multiple entry points (for example, investigating how individuals anticipate and imagine their own and their society's future, as well as the ways in which institutions and collectives undertake that imaginative work), and multiple approaches (from focused studies of exemplary texts to the discussion of discursive patterns and cultural tropes distributed across a broader textual corpus). As we will discuss in the subsequent section, we're pleased to introduce a suitably diverse range of approaches in the present volume.

Human agency in all its complexity is another key concern for sociologists, and the challenge of theorising how human beings, as individual and collective actors, can meaningfully and intentionally shape the future under conditions of social complexity and uncertainty is one that critical futures scholars need to keep in mind, even where that is not our primary focus. At the very least, we should exercise intellectual humility and remain wary of grandiose or simplistic premises: while Critical Future Studies work starts from the premise that access to the widest possible repertoire of images, stories, ideas and insights about potential futures is a fundamental prerequisite for any 'democratisation' of the future, this must necessarily be tempered by an awareness of the complex social conditioning and stratification of human agency.

Finally, this question of stratification (another central concern for sociologists) is itself an important one for us, as critical future scholars, to remain mindful of. Given our focus on cultural texts, it is not always possible to analyse in-depth the unequal distribution of power in terms of who gets to speak or be heard (or taken seriously) on the subject of the future. But such inequality is a fundamental ethical issue that should continue to shape our work, and one that we drew attention to in our original essay. We also called for attention to inequities to permeate our selection and critical readings of cultural texts: we proposed that one of the key ques- 
tions we should ask of the futuristic visions we analyse is "who would want to live in such a future?" and, by extension, who may thrive and who may suffer in such a future? Further to this (and something we perhaps did not foreground sufficiently at the time), we should take account of inter-generational power relations. Following Adam and Groves (2007), there is the vital question of whether and how future generations, whose futures we are actively shaping now, but who cannot 'speak' in a literal sense about their future, might nonetheless be granted some kind of 'voice' in the future-shaping discourses and practices of the present. We think it is entirely appropriate that such issues of inter-generational ethics play a prominent role in shaping the work of Critical Future Studies as it develops further.

While we are encouraged by the kind of futural scholarship referred to above which, as we've indicated, was already developing in our peripheral vision, we've also been heartened and inspired by the direct intellectual encounters to which our initial work on CFS has already led. Through presentations and correspondence relating to our original essay, we've discovered rewarding connections with colleagues from various countries who were already doing fascinating 'Critical Future Studies' work (even if they did not label it as such), and who were also energised by our work and wished to collaborate with us. We're delighted to present some of the resultant work in the present volume which, for us, represents the start, rather than the culmination of, a diverse, international and inter-disciplinary project that we believe, fittingly, has an exciting future. In the subsequent section, we will provide an overview of these diverse contributions.

\section{Looking forwards}

In this thematic section of Culture Unbound, we're pleased to present six diverse and thought-provoking articles. The first three all focus on technology-related topics (situated, of course, within their social and cultural contexts) while papers in the second half broaden the focus, highlighting cultural, political and economic issues and possibilities for re-imagining how society might be organised in the future.

Our first paper by Sy Taffel dissects the rhetorics and realities of green capitalist futures. Taffel's primary case study is Elon Musk's electric vehicle corporation Tesla and its spurious claims to help solve environmental problems with its 'clean' technology. As Taffel outlines, this imagined future depends on the occlusion of Tesla's real environmental impacts (as well as the negative impacts on indigenous communities arising from its dependence on Lithium and Cobalt extraction) in favour of an affectively appealing vision whereby (affluent) consumers can continue on the treadmill of luxurious consumption while saving the planet, one charge at a time. But Taffel's target is broader than Tesla alone: his paper critically 
explores the ways in which "technological solutionism", as a dominant future imaginary in contemporary society, treats the objectively incommensurable imaginary of "apocalyptic catastrophism" as a business opportunity, a discourse to be rhetorically domesticated within the frame of individualistic consumerism. This broad scope - the conjuncture of an ideologically dominant techno-solutionism and the spectre of ecological collapse - makes it an excellent paper with which to begin this special section, because it articulates in very stark terms what is at stake for the whole project of Critical Future Studies. Taffel's piece also highlights effectively the 'entanglements' of materiality, imagination and affect mentioned in the previous section. His critique is a materialist one, but he connects this to the affective dimension that we emphasised in our initial essay: the problem of hope. While Taffel is wisely circumspect about political responses, he shows that a rigorous materialist critique of solutionist future imaginaries is necessary but not, in itself, sufficient. The way forward, he suggests, lies neither in a neo-Luddite rejection of technology per se, nor in progressive or Left-wing versions of technological solutionism of the sort pursued by Nick Srnicek and Alex Williams in their influential work Reinventing the Future (2015). Rather, he looks to the cultivation of a 'fragile hope' through progressive social and political experimentation based on public good and commons based approaches to technological and social infrastructure.

Following from this, Luke Goode's paper on artificial intelligence (AI) similarly takes a Silicon Valley imaginary as its starting point, and also foregrounds the role of affect. AI is an increasingly influential social technology and one that has the potential to shape our future in ways that are both profound and hard to discern. As such, meaningful public debate about AI and its role in the future is both necessary and difficult. Citizens rely on popular media to stimulate insight and interest into a complex topic such as AI and there are good reasons to claim (as many experts now do) that the public is not well-served at present, because highly sensationalised media stories typically focus on spectacular and cutting edge developments rather than the forms of AI that are more quietly but more influentially reshaping society. Non-fictional media coverage also draws heavily on science fictional tropes (tropes of an AI uprising, AI 'going rogue', and sentient AI, for example) in ways that annoy experts keen to educate the public about the more prosaic realities. But Goode's paper rejects as simplistic the assertion that we just need a more sober and rational public discourse about AI. Coverage of the topic draws on historically and culturally embedded imaginaries of both the 'technological sublime' and the 'uncanny'. His paper ranges across science fiction representations, popular science speculations about an impending AI 'singularity', and examples of prominent recent AI developments that have attracted widespread media and popular attention because of their capacity to evoke both wonder and anxiety. Rather than wishing them away as irrational blights on the public imagi- 
nation, these 'evocative stories' must somehow be harnessed as entry points into more meaningful public conversations about the role we want AI to play in our future.

Many of the characteristics of contemporary public 'debate' around AI are scarcely new, however, and we have much to learn from historical examples. Daniel Bodén's article is a careful and insightful examination of a particular slice of the technological imaginary within Western modernity, and one that has broader resonance with contemporary debates. Specifically, he draws on a corpus of articles from the 1950s in the Swedish press that deal with industrial automation through the trope of an 'impending robot revolution'. He begins with discussion of a series of evocative sketches that accompanied the articles. These conveyed a more mixed attitude of hope and anxiety compared to the articles themselves, which largely reflected the dominant progressivist imaginary of the time. A key part of the ideological work that these texts perform is to naturalise visions of a 'prosperous' automated future through repeated appeals to 'inevitability' (something we identified as a key feature of contemporary Silicon Valley ideology in our original essay). Bodén situates this historical analysis within the theoretical framework of technological fetishism. These mid-century texts, he reveals, relied heavily on the anthropomorphic figure of the robot, and on metaphors of the living body to describe the automated factory (robotic 'arms', sensors envisioned as eyes, control banks as brains), and ascribed the machines agency. In that sense, they performed the ideological function of instantiating 'dead labour' as 'living labour' and rendering concrete the otherwise abstract forces of competition and productivity to which the project of automation was geared. Yet, in keeping with other CFS scholars, Bodén is careful to point out that futural texts such as these are more than mere ideology and, in their invocation of the 'not-yet' (Bloch 1995[1954]: 110), also contain within them a utopian potential. The challenge, he asserts, is not merely to unmask their ideological work but also find ways to redeem the utopias contained within them.

Historical perspectives, such as Bodén's, are a critical part of the CFS enterprise. As historian Roxanne Panchasi reminds us: "the future anticipated at a particular historical moment can tell us a great deal about the cultural preoccupations and political perspectives of the present doing the anticipating" (Panchasi 2009: 4). But another important lens for studying the anticipatory concerns of particular moments is science fiction. This genre is less about forecasting future technologies (such as mobile phones or virtual reality) than it is about posing questions and reflecting concerns over the possible impact of science and technology on society (cf. Godhe 2018). In her article, Josefine Wälivaara analyses how marginalised bodies - in this case characters with physical disability and homo/bisexual characters - have been depicted in popular science fiction film and television. While 
many claim the potential in science fiction to contest tendencies in the present and offer possible future alternatives, it is equally important to examine how present-day ideals and norms are reproduced in images of the future. As a futural public sphere, science fiction is capable of both contesting and reinforcing cultural and political hegemony. For Wälivaara, even if queer and disabled characters are becoming more common in science fiction futurescapes, they remain marginal compared to the large quantity of science fiction film and television being produced, effectively reproducing heteronormative and ableist ideologies. Wälivaara quotes Brian Attebery (2002: 191) to underscore what's at stake here: "Any group that cannot negotiate a place for itself in the imagined future is already obsolete".

The unemployed are another marginalised group that have to contend with socially ascribed 'obsolescence' - and automation raises the prospect of a radical increase in the size of this group in the future. This is the subject of Michael Godhe's essay. Automation, robotisation and the development of artificial intelligence have been on the agenda in recent years, and the hopes and fears surrounding these development are debated in many arenas, not least the daily press (cf. Bodén's contribution in this thematic section). While some people fear that we are facing a future of mass unemployment, others see bright prospects for humanity. Some scholars and public intellectuals claim that the central role that work plays in society will soon be a relic of the past, deploying phrases like "post-capitalism" and arguing for universal basic income to meet the challenges of a post-work society. Godhe discusses the question of work in relation to the computerisation of society through the lens of science fiction. As he shows, the question of the value of work and the relationship between work and leisure have been discussed since ancient times. For a long time, work was a central issue in utopian and dystopian literature, in fiction as well as non-fiction. With few exceptions, work wasn't abolished but rather reduced and the question was to improve the working conditions. But recent speculative fiction as been more open to imagining the end of the work-based society. As a case, Godhe investigates the Thousand Cultures tetralogy (1992-2006) by John Barnes, posing questions such as: What if we could create post-scarcity societies with an abundance of goods and services created by moreor-less intelligent machines, making manual wage labour unnecessary? What are the pros and cons of such a future? In Barnes's tetralogy, as Godhe shows, identity connected to work is replaced with identity connected to cultural belonging, and in the worst case leads to aggressive identity politics with xenophobic tendencies. Godhe's article suggests that we can use science fiction as a resource for rethinking society and the notion of work in the future.

Such rethinking may, in fact, entail the ability to think beyond capitalism. Perhaps capitalism as we know it is incapable of solving and adapting to the challenges and crises of our time. But anti-capitalist and specifically socialist thought (in 
its different versions) need to be rethought as well. In their article, Monica Quirico and Gianfranco Ragona, explore the work of four socialist thinkers that share an 'elective affinity': Alexandra Kollontai (1872-1952), Paul Mattick (1904-1981), Raniero Panzieri (1921-1964) and Alain Bihr (b.1950). Quirico and Ragona show how each of these thinkers contribute to the project of rethinking possibilities for a future beyond capitalism. In different ways, they all contribute to a radical critique of capitalism without falling back into the pathologies of party dictatorship and Soviet socialism, opposing the notion of an avant-garde leading the transformation of society. Instead, they argue for self-government, "for a bottom-up, self-guided organization" that avoids bureaucracy and authoritarianism, that is, "the direct mobilization of the masses in economic, political and social life". At the end of their article, Quirico and Ragona show the relevance of these thinkers today through a case study: the Movement for a Democratic Society in the Rojava region of Syrian Kurdistan.

We hope and, indeed, anticipate that the articles in this special theme section will be of interest to a broad range of readers, and that they will stimulate further work along the lines of Critical Future Studies. Certainly we believe that they each have something valuable to say about the ways in which culture may shape the future and vice versa. And we hope that readers will agree that they are, in themselves, small but useful contributions towards expanding the range of imaginable futures that lie before us.

Michael Godhe is Senior Lecturer at Culture, Society and Media Production (KSM) at the Department for Studies of Social Change and Culture, Campus Norrköping at Linköping University. He is currently finishing a book on the mediatization of the space project in Sweden 1900-1957. E-mail: michael.godhe@liu.se

Luke Goode is Associate Professor of Media and Communication at the School of Social Sciences, University of Auckland, Aoteaoroa New Zealand. His teaching and research interests focus on new media technologies and their social and political impacts, digital culture and science fiction. E-mail: 1.goode@auckland.ac.nz

\section{References}

Adam, Barbara and Chris Grove (2007): Future Matters: Action, Knowledge, Ethics, Leiden: Brill.

Attebery, Brian (2002): Decoding Gender in Science Fiction, New York: Routledge.

Bloch, Ernst (1995[1954]): The Principle of Hope, Volume One, Cambridge, MA: The MIT Press.

Bowler, Peter J. (2017): A History of the Future: Prophets of Progress from H.G. Wells to Isaac Asimov, Cambridge: Cambridge University Press.

Frängsmyr, Tore (1990): Framsteg eller förfall: Framtidsbilder och utopier $i$ västerländsk tanketradition, Stockholm: Allmänna Förlaget. 
Godhe, Michael (2018): “The Old Stories Had Become Our Prison': Globalization and Identity Politics in John Barnes's Science Fiction Novels A Million Open Doors and Earth Made of Glass", Fafnir: Nordic Journal of Science Fiction and Fantasy Research, 5:1, forthcoming.

Goode, Luke and Michael Godhe (2017): "Beyond Capitalist Realism - Why We Need Critical Future Studies", Culture Unbound: Journal of Current Cultural Research, 9:1, 108-129.

Levitas, Ruth (2010): "Back to the Future: Wells, Sociology, Utopia and Method", The Sociological Review, 58:4, 530-547.

Levitas, Ruth (2013): Utopia as Method: The Imaginary Reconstitution of Society, London: Palgrave.

Miller, Riel (2007): "Futures Literacy: A Hybrid Strategic Scenario Method", Futures, 39:4, 341-362.

Miller, Riel (2018): Transforming the Future: Anticipation in the 21st Century, London \& New York: Routledge. http://unesdoc.unesco.org/images/0026/002646/264644E. pdf

Panchasi, Roxanne (2009): Future Tense: The Culture of Anticipation in France between the Wars, Ithaca, NY: Cornell University Press.

Poli, Roberto (2010), "The Many Aspects of Anticipation", Foresight, 2010, 12:3, 7-17.

Schulz, Markus S. (2015): "Future Moves: Forward-Oriented Studies of Culture, Society, and Technology", Current Sociology, 63:2, 129-139.

Srnicek, Nick and Alex Williams (2015): Inventing the Future: Postcapitalism and a World Without Work, London: Verso.

Son, Heonju (2015): "The History of Western Future Studies: An Exploration of the Intellectual Traditions and Three-Phase Periodization", Futures, 66, 120-133.

Tutton, Richards (2017): "Wicked Futures: Meaning, Matter and the Sociology of the Future", The Sociological Review, 65:3, 478-492. 